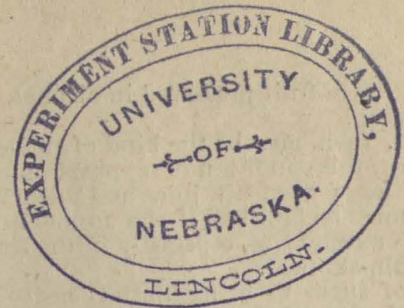

\title{
UNIVERSITY OF CALIFORNIA.
}

\section{AGRICULTURAL EXPERIMENT STATION.}

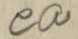 \\ BERKELEY，CAL.
}

BULLETIN NO. 86.

+

\section{PRESERVATIVE FLUIDS FOR FRESH FRUITS.}

As the fruit season approaches there is a constant inquiry for some mode of preserving fruit samples for exhibition at the several fairs. As a general answer to inquiries of this kind that have already come dropping in, I give the following data in regard to the more successful preservatives that are within reach of the practice of any intelligent farmer. I preface them with an explanation of the demands made upon such preservative methods, for the bentfit of those to whom the subject may be new, in order that they may better adapt their practice to circumstances.

1. The preservatives must prevent all fermentation, molding, or other fungous attacks. This, of course, means that the outside of the fruit, and the air or liquid around it, shall be "sterilized" in some way compatible with the preservation of the form, at least, of the fruit or vegetable. This, again, excludes any considerable heating, such as is necessary in "putting-up" fruit for eating purposes. We are practically reduced to the use of antiseptics, acting at the ordinary temperature. Among these we have to choose between gases and liquids; but as the manipulation of gases does not come within the condition of easy practicability in an ordinary household, we are further confined to the use of liquids only; the more as these help to prevent damage in transportation, by removing the greater part of the weight of the individual fruits, that would tend to deform them. Hence

2. The preservative should be a liquid. This liquid, besides being an efficient antiseptic, should not exert any solvent or softening action upon the skin of the fruit. This condition excludes from the outset all alkaline solutions (such as e. g., cyanide of potassium, silicate of soda, etc.) and all of the stronger acids lncluding acetic acid or vinegar.

3. The antiseptic fluid should not extract or change the color of the fiuit. This is one of the most difficult conditions to fulfill, and yet one of the most essential. It excludes at once so excellent a preservative as alcohol, and many others that would otherwise be available; among others, common salt.

4. The preservative fluid should neither cause the fruit to swell, so as to increase its size, and sometimes burst it; nor should it have the opposite effect of causing it to shrink. This implies that in the exchange that will unavoidably occur between the juice inside and the fluid outside, the two shall pass through the skin with about equal rapidity. According to well-known physical laws, this necessitates that the two liquids shall be approximately of the same density. Thus, if the fruit to be preserved were grapes containing a juice showing 25 per cent by spindle, the fluid outside ought to be made of about the same density. 'If not, the fruit will either shrink or swell, at least at first; in some cases the original bulk will ultimately be recovered; but usually, particularly in thin-skinned fruits, the change is more or less permanent. Thus in pickling ripe olives, the size of the fruit may be materially reduced, and their substance toughened when too soft, by the use of strong brine. The same is pre 
eminently true of fruit preserved in alcohol, or in strong syrup.

Whatever, then, may be the kind of antiseptic employed, this condition of approximately equal densities of the fruit juice and preservative fluid must be fulfilled if the former is to maintain its natural size, especially if the fruit be soft or thin-skinned.

The use of sugar to bring up the density of the antiseptic solution to that of the fruitjuice, naturally suggests itself, and with some fruits very good results may be obtained in that way. Still, sugar being itself easily fermentable and liable to change tint when not very pure, it is preferable to use glycerine, which cau now be obtained so cheaply as to render it available to all, and which is for practical purposes unchangeable when so used. According to actual trial, commercial "pure" glycerine will act very satisfactorily when used per cent for per cent in place of sugar. To do this by liquid measure, use 4-5 per cent of glycerine as equal to 1 per cent of sugar.

Like alcohol, however, glycerine exerts a slight solvent action upon many fruit colors; $e . g$., that of cherries, blackberries, etc.

Common salt has the disadvantage of darkening all vegetable colors after a comparatively short time; and Glauber's salt, alum, and other commonly available salts exert a not inconsirerable solvent action upon colurs, which renders their use inadvisable.

It is not always, of course, easy to ascertain the density of the juice of fiuits; but the housewife or farmer may rest content with the following approximations to the soluble matters of fruit juices:

Apples and pears about 12 per cent.

Plums, prunes, apricots, peaches, about 10 per cent. Cherries about 12 per cent.

Most berries, 8 per cent.

Currants, 10 per cent.

Grapes, in California, 18 to 32 per cent, average 24 per cent.

It is only in very tender-skinned fruit that a per cent or two more or less will make a difference in the result.

Of antisentics the following are the most available: Salicylic acid; boracic acid; sulphurous acid, and its compound, bisulphite of soda (and of lime); last but not least, bichloride of mercury or corrosive sublimate.

Salicylic acid, or its compound with soda, both obtainable in commerce, is one of the best and most energetic antiseptics. Its use in spirituous fluids is but too well known; in watery solution it is not so much used on account of some difficulty in making it dissolve, particularly when the water is cold. An ounce of the acid dissolves in a little less than five gallons of water at the ordinary temperature; but when it is simply thrown on the water it may float there a long time, being very light, and most persons will think that it will not dissolve in that proportion. In hot or boiling water there is no difficulty, and the solution is made very easily by the addition of a little carbonate of soda (salsoda) even without heating. But when making use of the soda it is absolutely necessary to avoid an excess, as the uncombined soda exerts a very injurious influence upon the preservation of fruits.

A solution of one ounce of salioylic acid to five gallons of water, to which as much glycerine has been added as corresponds to the density of the fruit juice (see above), constitutes a preservative fluid which has been used with very satisfactory results heretofore. Trouble has arisen from the use of too much soda in making the acid dissolve; as already stated, with patience or heating, the water alone will dissolve the acid, and soda need not be used at all.

Boracic acid, while an excellent preservative so far as the mere prevention of decay or fermentation goes, is more liable than the salicylic to soften the skin and alter the colors of fruit, acting in that respect, in some cases, like alkaline solutions. It is therefore not well adapted to long conservation of samples in their natural aspect, but will do well for a few weeks with most fruits. Use the solution as strong as water will make it, which is about five ounces per gallon.

Sulphurous acid, the same substance of which the use is so much abused in fruit-drying, and in the treatment of wines, can also be emploved in solution for the preservation of fruits. This solution may be made directly from the gas of burning sulphur-by an operation sufficiently familiar to cellarmen and described below. It is, however, more convenient and just as good to use its combination with soda, viz., the "bisulphite" of soda (not that of lime, used in bleaching saccharine juices, as it will form deposits upon most fruits), heretofore sold under the fanciful name of "California fruit salt," and recommended for use in canning fruit for human consumption. Those whose digestion is better than necessary, and who do not object to the sulphurous flavor of the fruit so preserved, may choose to so use the preparation. Its merits as an antiseptic are unquestioned; its bleaching effects are equally so, and as in sulphuring wines, the natural colors will suffer more or less from its use, as well as from that of the acid solution. Use 5 to 8 ounces per gallon.

The following mode of preparing a preservative fluid with sulphurous gas, obligingly communicated by Manager J. Q. Brown, has been very successfully used at the rooms of the State Board of Trade at San Francisco:

"Put 30 gallons of water into a 40 -gallon barrel; float on top of the water a tin pan, in which put a portion of 25 cents' worth of sulphur. Set the sulphur on fire and cover tightly until the fire goes out; renew the sulphur until the whole is consumed, opening the barrel for renewal of air between the doses."

While this mode of pioceeding is somewhat wasteful of sulphur and could be improved upon by a cellarman, vet it is so simple, and sulphur is so cheap, that it may well be recommended for use on the farm.

Quite lately the use of mercuric bichloride or corrosive sublimate for this purpose has been brought prominently forward by Prof. P. Pichi, of the laboratory for botany and vegetable pathology in the Royal Viticultural School of Conegliano, Italy. In an article published in April number of the official journal of that school, Prof. Pichi discusses the requirements for the preservation especially of collections of grapes, probably the most difficult of all. $\mathrm{He}$ states that after experimental trials of all the usual preservative solutions, such as alcohol of various strengths, and of watery solutions of salicylic, boracic and other acids, and salts of copper, he finally made trials with solutions of corrosive sublimate ranging from 1 to 4 pro mille in strength. After two months, all were still in perfect preservation, both as to color, form and 
size, and the berries remained firmly attached to their stems. After five months the fruit in the $1 \mathrm{pm}$. solution was in a decidedly unsatisfactory condition, and after the first year, unfit for study; while those in the stronger solutions were in good condition, but the fluids were of a slightly reddish tinge, particularlv in the $2 \mathrm{pm}$. solution. After four or five months more this difference against the weaker solutions was still more pronounced, and it was evident that $3 \mathrm{pm}$. is the least strength compatible with good conservation. A second series of experiments confirmed this, and pointed to a solution of $4 \mathrm{pm}$. as probably the best. The final conclusions are stated as follows:

"From all that has been here reported I believe the conclusion to be justified that grape bunches can be best preserved for collections by keeping them immersed in a solution of corrosive sublimate, taking special care to wash them thoroughly beforehand. The best strength for this solution appears to be 4 pro mille; it will probably be advantageous to renew the solution at the end of the first two years, and perhaps subsequently at similar intervals; but we shall thus have assured the preservation of the grapes, with all their exterior natural characters, and with but a trifling expense, for a number of years."

The author finally calls attention to the poisonous nature of the preserving fluid, which is, however, the same used in pathological iaboratories for the disinfection of hands and instruments after use in anatomical dissections.

The strength above referred to as the best is equal to half an ounce of corrosive sublimate to a gallon of water. Nothing is said by Prof. Pichi regarding the addition of glvcerine or anything else to correct the density of the solution; and it is possible that the hardening of the grape-skins, caused by the action of the sublimate, renders such addition unnecessary. If so, this would certainly be both the most perfect and the cheapest method of satisfactory preservation thus far found; the possibility of dangerous mistakes of such specimens for ordinary "put-up" fruit alone excepted. Its merits with respect to other fruits than grapes are now under trial at this station, and will be fully tested during the coming season on all available fruits.

The solution should properly be made with distilled water; when this is not available, other water may be used, preferably that from the larger streams; but (particnlarly in the case of well water) it should first be boiled and allowed to clear by settling, before dissolving the sublimate. Even then a whitish or grayish turbidity and sediment will usually form after a while; this should be allowed to settle fully before putting the flaid over the fruit. It would be well to label all such fruit jars "POI3ON," for the sake of safety. No metal must come in contact with the sublimate solution, as it would be quickly decomposed.

\section{THE SULPHURING OF DRIED FRUITS.}

The writer's views on the above subject have been so often expressed before meetings of fruit-growers, and in print before the general public, that it might seem uncalled-for to reiterate their formal expression in this place. Yet the frequent requests, both written and verbal, for such expressions, seem to render it the briefest mode of disposing of the subject; the more as the only radical solution of the question lies in its being more and more fully understood by consumers (to whom these presents are equally addressed), who now sacrifice good flavor and healthfulness to mere appearance.

The sulphuring of dried fruit has two chief objects. One, and that most generally kept in view, is the brightening of the color, which always darkens, particularly in sliced fruit, in whatever way it may be dried; the change of color being due to the action of the air (oxygen) upon certain easily changeable substances contained in all fruits. This darkening (mostly to a light brown) is a practically inevitable result of drying any fruit in contact with air, whether in sunshine or by artificial heat, and should belooked for by every consumer, as the natural mark of an honest, unmanipulated article.

The second object sought to be attained bv sulphuring is to render the fruit secure from the attaciss of insects; whether by renderin : its surface unpalatable before the eggs are lairl. or by killing eggs laid during sun-drying, that might subsequently hatch in the packages. The latter object involves, of course, the sul. phuring of the dried fruit, the former is to a greater or less extent attained by sulphuring before drying.

The effects of sulphurous acid (the gas-not the visible fumes-given off from burning sulphur) as a disinfectant and bleaching agent, are generally understood. The gas is absorbed by the moisture of the fruit, to an extent depending upon the time of exposure, its fresh or dried condition, and the amount of sulphur used.

When freshly sliced fruit is sulphured for a short time, the gas penetrates only " skindeep;" and when the fruit is afterward dried, whether in the sun or drier, most of the gas escapes and few persons would note the difference in taste produced thereby. Insects, nevertheless, are to a very material extent deterred from touching such fruit.

But when the latter is dried and then thoroughly sulphured, as is too commonly done, the effect is much more serious. The gas then penetrates the entire spongy mass, bleaching it, so that carelessly dried fruit, too dark to be marketable, can thus be made to appear more or less inviting to the eye. Not, however, to the nostrils or to the taste, for with the color the flavor has also suffered correspondingly; ani upon opening a package of such fruit, instead of the natural aroma, there apuears the flavor familiar to those who visit a chemical labora torv, or acid manufactory.

The consumer then has reason to object to dry-sulphured fruit on two counts, either of which is sufficient to condemn the practice. One is that dirty, ill-prepared or damaged fruit may thus he imposed upon him for good qual ity; the other, that the natural flavor of the fruit is either seriously impaired or sometimes almost completely destroyed, and (as will be shown) its acidity greatly increased.

There is another and very serious count in the indictment, namely, that such fruit is un- 
healthy because containing an antiseptic that impedes digestion, and while the fruit is relatively fresh, causes headaches just as will sulphnred wine. After some time, the "sulphurous" acid originally introduced becomes converted into "sulphuric" acid, a condiment that few will desire to consume in their daily food. The precise extent to which this may be present is shown in the subjoined analyses, respectively of apricots sulphured before and "Silver prunes" sulphured after drying, as found in the market:

Total Acidity* Sulphuric acid Per cent (SO 3). Per cent.

Non-sulphured apricots... Sulphured apricots..........
Non-sulphured prunes..... $\begin{array}{ll}\text { Non-sulphured prunes...... } & .321 \\ \text { Sulphured prunes............. } & .514\end{array}$ 067 (combined) .232 (mostly free) .056 (combined) .346 (mostly free)

In considering the above results, it should be understood that the sulphuric acid given as contained in the unsulphured fruit is present in the forn of " neutral salts," such as occur in the ash of all vegetable products; while that which is added in sulphuring exisis in the form of free acid.

It will be seen that in the case of the apricots the increase was to the extent of about twice and a halt the amouıt originally present, although these were reported to have been sulphured only before (more probably during) drying. Their lack of $\mathrm{r}$ atural flavor and pungent acid taste at once revealed the effects of sulphuring.

In the prunes, which had been sulphured after drying, the effect was much more striking. Here the increase was to sver six times the natural contents. The total amount added by sulphuring amounted to nearly a third of one per cent, and the free sulphuric acid in the dried fruit amounts to .22 per cent, which is equivalent to about 25 grains of commercial oil of vitriol per pound.

In addition to rendering the fruit unpalatablv acid, it had been rendered obnoxious both to the digestive organs and to the teeth. No one could habitually consume such fruit without feeling the effects of such an amount of mineral acid, introduced into his food purely for the gratification of the eye with an unnatural tint.

But so long as the public, and its agents the dealers, continue willing to pay from 30 to 50 per cent more for the whitened sepulchres of fered them in the shape of sulphured fruit than for that which retains, with its natural flavor and sweetness, the natural tint of dried fruit, and with it the marks of careful or careless treatment, so long will the producer continue to supply the demand for the doctored article; unless, indeed, the law should intervene, as has been done in most European countries. There

\footnotetext{
*Expressed in terms of sulphuric acid.
}

the sale of sulphured rruit is simply forbidden as injurious to public health, and as coming under suspicion of having been "doctored up" from an inferior article with fraudulent intent.

When, therefore, it is asked what I think is the proper policy to be pursued in this respect by a region which this year will for the tirst time come into the dried-fruit market, I reply that I think the time has come to make a step forward and try to put upon the market a firstclass article of " unsulphured dried fruit," with the express statement and claim that it is unsulphured and retains the natural sweetness and flavor of California fruit, instead of being reduced to a common level with the worst products of any other country. For it is cerain that the whitish-green dried apples and pears now sold at high prices in our grocery stores might just as well have been grown anywhere from Norway to the Mediterranean for aught they teach of the quality of our fruits.

The following suggestions are offered to those who are willing to practice sulphuring to a moderate degree only, and with some regard to the conservation of the fruits' palatableness:

Large quantities of sulphur introduced at once into the drier or sulphuring-box will tend to cause a deposit of sulphur, in substance, on the outside of the fruit, adding its flavor to that of the acid, which alone is useful. The less sulphur is put in at one time, and the more air admitted, the less there will be of the visible fumes that carry the sulphur up into the fruit. It is best to let the sulphur catch fire all over before putting it into the box at all.

Let whatever sulphuring you must do be done before drying, as in that ca e not only will the drying process itself drive off a great deal of the superfluous acid and prevent it from penetrating the whole, but the flavor of the interior will penetrate outward and measurably do away with the laboratory odor that will otherwise pervade the fruit pack age.

A very sightly and appetizing cinnamonbrown tint for sliced apples and pears may be secured by dipping, for a few minutes, the freshly made slices, contained in a properly shaped basket (of galranized wire if desired), into a solution of salt containing not less than two ounces in five gallons of water. This prevents any spotting where the fruit has been touched. Instead of the salt, a similar solution of the bisulphites of soda or lime may be used, which effect a slight external bleaching without injury to the flavor of the fruit.

Last, but not least, let us try to gradually educate the public taste up to the point of preferring in this matter the substance to the shadow, and accepting healthy, brown, highHavored dried fruit to the sickly-tinted, chemical-tainted product of the sulphur box.

E. W. Hilgard.

Berkeley, May 17, 1890. 